\title{
Temporal and Spatial Water Quality Assessment for Rivers in Metropolitan Areas Using Multivariate Statistics and Water Quality Indices: A Case Study of the Geumho River, Korea
}

Chang Dae Jo

National Institute of Environmental Research

Jung Min Kim

National Institute of Environmental Research

Seong Min Kim

National Institute of Environmental Research

Heon Gak Kwon ( $\sim$ hun7082@korea.kr)

National Institute of Environmental Research https://orcid.org/0000-0003-2153-037X

\section{Research Article}

Keywords: Geumho River, Principal analysis, Factor analysis, Cluster analysis, Discriminant analysis, Korean Water Quality Index

Posted Date: December 20th, 2021

DOl: https://doi.org/10.21203/rs.3.rs-1087269/v1

License: @ (i) This work is licensed under a Creative Commons Attribution 4.0 International License. Read Full License 


\section{Abstract}

The Geumho River in South Korea passes through a metropolitan area with a high population density and multiple industrial complexes and, therefore, the water quality of this river is of significance for human health and economic activities. This study aims to assess the water quality of the Geumho River to inform river water quality management and improve pollution control using multivariate statistics and the Korean Water Quality Index (KWQI). Principal component and factor analysis identified those factors related to organic pollutants and metabolism (principal factor 1), and phosphorus and fecal coliform content (principal factor 2). In a cluster analysis, time was considered by distinguishing between seasons (spring, summer, autumn, and winter) and space was considered based on upstream (US), midstream (MS), and downstream (DS) river sections. Seven temporal variables and six spatial variables were extracted from the discriminant analysis (DA) results; the most important water quality variables were high during the spring and summer seasons and in the MS and DS regions. Temporally, the KWQI was highest in winter (70.9) and lowest in spring (59.2), whereas spatially, KWQI values were highest in the US (67.5) and lowest in the MS (56.4) sections. These results indicate that to be most effective, water management interventions in the Geumho River should focus on the urban midstream section and spring seasons.

\section{Introduction}

The water quality of a river is affected by pollution (e.g., from nonpoint sources and non-biodegradable organic matter) generated from natural processes, urbanization, and regional development often in association with agricultural and industrial activities (Li et al. 2015; Zeinalzadeh and Rezaei 2017; Wu et al. 2018). When the self-purification capacity of a river is exceeded due to the inflow of such pollution sources, environmental problems occur including poor water quality (Salla et al. 2014; Wen et al. 2017). In the past, organic matter management through biochemical oxygen demand (BOD) regulation was possible because most pollutants were predominantly biodegradable. However, with advances in industry and rapid urbanization, the use and release of inorganic chemicals and non-biodegradable organic matter have increased (Park et al. 2013; Jung et al. 2015). As a result, the inflow of excessive nutrients to rivers can cause serious environmental problems including algal blooms, eutrophication, and large-scale fish kills. To effectively manage surface water quality, it is very important to control the pollution sources affecting rivers by collecting reliable data, assessing temporal and spatial water quality dynamics, and analyzing the causes of water pollution (Tian et al. 2019; Nong et al. 2020; Varol 2020).

Various statistical analysis techniques have been used to monitor water quality in rivers including multivariate statistical techniques (MSTs), such as principal component analysis (PCA), factor analysis (FA), cluster analysis (CA), discriminant analysis (DA), and analysis of variance (ANOVA) (Shrestha and Kazama 2007; Fan et al. 2010; Barakat et al. 2016; Chai et al. 2020). These methods inform water resource management by enabling the assessment of key factors affecting water quality and their temporal and spatial dynamics. Indeed, worldwide, many studies have sought to assess river water quality patterns and dynamics using various statistical techniques, and propose measures to rapidly solve pollution and associated water-quality problems (Li et al. 2018; Wu et al. 2018; Gurjar and Tare 2019; Ustaoğlu et al. 2020). 
With increasing industrialization and urbanization worldwide, the management of rivers in metropolitan areas is becoming more important (Ren et al. 2018; Xu et al. 2019; Yang et al. 2021). In the case of the Geumho River in South Korea, the upstream section is relatively clean while nonpoint pollution sources discharge into the river under certain rainfall conditions. In contrast, there are multiple pollution sources along the midstream section, which flows through a metropolitan city; yet, current water quality management in the Geumho River Basin focuses on BOD and total phosphorous (TP) concentrations only in the downstream section.

In this study, the water quality characteristics of the Geumho River are assessed using both MSTs and the Korean Water Quality Index (KWQI), the combination of which is judged to be an effective method for evaluating water quality characteristics relative to their individual use. The main aim of the study is to evaluate the spatial and temporal characteristics of water quality in the river and determine the main contributing factors. In doing this, this study provides a useful tool for identifying the causes and dynamics of pollutants found in rivers passing through other metropolitan areas so that appropriate and targeted water quality control measured can be developed.

\section{Material And Methods}

\subsection{Study watershed}

The Geumho River originates in Pohang City and passes through Daegu Metropolitan City via Yeongcheon Dam, Yeongcheon City, and Gyeongsan City (Fig. 1). There are more than 20 main inflow tributaries to the Geumho River including the Shinryeongcheon, Bukancheon, and Cheongtongcheon in the upstream area, and the Omokcheon, Namcheon, Shincheon, Palgeocheon, Dalseocheon, and leoncheon in the downstream area. These combine and flow into the Nakdong River. The average annual precipitation in the Geumho River watershed is $1,089 \mathrm{~mm}$, which is significantly lower than the national average of $1,159 \mathrm{~mm}$ (https://data.kma.go.kr). In particular, water quality deteriorates during the relatively dry season (January to April) due to a lack of instream flow, whereas rainfall is concentrated during the flood season (July to September) (Choi 2004; Gawk, 2020).

The upstream section of the river is relatively clean, although some agricultural and livestock nonpoint pollution sources exist. In the midstream and downstream sections, the pollution loads rapidly increase due to the presence of large industrial complexes and dense urban areas (Yang and Bae 2012; Nkomozepi and Chung 2014; Jung et al. 2016). In addition, in the downstream section of the river, there is concern over the inflow of nonpoint sources during rainfall events from widespread greenhouse farming. Indeed, frequent inflows of highconcentration pollution sources have occurred in the past due to rapid industrialization and urbanization, contributing to a poor water quality status (MOE 2000, 2005). Although water quality has been greatly improved through continuous management, the inflow of various pollutants continues to be a problem. In particular, the industrial complexes within the basin generate large amounts of wastewater treated in large sewage treatment facilities (STFs) and wastewater treatment facilities (WTFs) and subsequently discharged into the river. These effluents introduce a range of pollutants (e.g., non-biodegradable organic matter, nutrients, and heavy metals) into the river as it passes through the urban areas (Park et al. 2016; Shin et al. 2018; Xu et al. 2019). Therefore, further water quality management interventions are urgently required to target these pollutants.

\subsection{Water quality analysis}


Water quality monitoring was conducted once a month from 2017 to 2020 at six sites (Fig. 1) in the Geumho River Basin (Fig. 1), data for which were obtained from the Water Environment Information System database (http://water. nier.go.kr). For each of the surface samples collected from each site, 15 water quality variables were measured in accordance with the official test methods for water pollution in Korea (MOE, 2008). Water temperature (WT), pH, dissolved oxygen (DO), and electrical conductivity (EC) were measured directly (YSI 6600 EDS, USA); and BOD, chemical oxygen demand (COD), total organic carbon (TOC), total suspended solids (TSS), total nitrogen (TN), nitrate-nitrogen $\left(\mathrm{NO}_{3}-\mathrm{N}\right)$, ammonia-nitrogen $\left(\mathrm{NH}_{3}-\mathrm{N}\right)$, TP, phosphate-phosphorus $\left(\mathrm{PO}_{4}{ }^{-}\right.$ $\mathrm{P})$, chlorophyll-a (Chl-a), and fecal coliform (FC) were determined in the laboratory in accordance with official test methods (MOE, 2008) using samples transported from the field in an icebox.

\subsection{Statistical analysis}

Multivariate statistical analysis of water quality was conducted using CA, PCA, FA, and DA techniques. The data for the 15 water quality variables (2017 to 2020) for the six monitoring sites were used in these tests. All data were standardized using z-scores to prevent errors resulting from the different measurement units of each variable. For all statistical calculations and figures, SPSS 24.0, XL-STAT 2020, and Arc-GIS 10.5 software programs were used.

\subsubsection{PCA and FA}

PCA is a statistical technique used to reduce dimensions by extracting eigenvalues and eigenvectors from a covariance matrix using the correlations among variables (Sarbu and Pop 2005; Barakat et al. 2016). An eigenvalue represents the magnitude of variance that can be explained by the principal component; an eigenvalue $>1.0$ indicates that one principal component can explain one or more variables. FA generates a new component (varifactor, VF) by rotating the PCA result using the maximum variance method to reduce the influence of the variables of low importance (Dominick et al. 2012; Liu et al. 2020). Therefore, eigenvalues $\geq$ 1.0 were extracted and analyzed here. To assess and verify the suitability of the data for FA, Kaiser-Meyer-Olkin (KMO) and Barrett's tests were first conducted (Shrestha and Kazama 2007; Li et al. 2018). In the FA results, loading values $>0.75$ were classified as "strong" and those between 0.5 and 0.75 were classified as "moderate" (Liu et al. 2003).

\subsubsection{CA}

CA is a statistical technique used to classify data by analyzing the differences or similarities among observed values. Hierarchical CA can significantly reduce the dimensionality of data by classifying clusters into homogeneous groups. In general, the similarity between samples is measured using the Euclidean distance, and the distance between clusters is measured using Ward's method (Zhang et al. 2009; Fan et al. 2010; Azhar et al. 2015). Here, the 15 different characteristics of the study watershed were investigated based on temporal and spatial classification. In addition, the results of the CA were used as the pre-classification values for the DA.

\subsubsection{DA and ANOVA}

DA is a statistical technique used to derive a group classification discriminant through the explanatory variables of data groups and classify the groups accordingly (Li et al. 2018; Varol 2020). The technique minimizes classification errors when data are classified into two or more groups by calculating a linear 
discriminant function, and predicts and confirms the group of dependent variables using independent variables derived from quantitative data. In this study, DA was performed according to the temporal and spatial classifications based on the CA results. DA was conducted in standard and stepwise modes, and the results were compared and evaluated. ANOVA compares the variability of two or more groups by comparing the variance within the groups (Rogerson 2019). Here, one-way ANOVA was performed to examine the homogeneity between the stepwise DA groups. A post-hoc analysis was performed using the Scheffe Test to examine the effect of the different temporal and spatial groups on each of the 15 water quality characteristics.

\subsubsection{KWQI}

The KWQI was calculated and evaluated for each of the temporal and spatial groups of the study watershed, as is utilized by the Ministry of Environment of Korea (NIER 2013). The KWQI considers seven variables (pH, DO, EC, WT, TOC, TN, and TP) and was calculated as follows:

$$
K W Q I=100-\sqrt{\frac{F 1^{2}+F 2^{2}+F 3^{2}}{3}}
$$

where $F 1$ is the fraction calculated by dividing the number of water quality variables that violate standards by the number of all measured water quality variables; $F 2$ is the fraction calculated by dividing the total number of standard violations by each water quality variable during the measurement period by the total number of measurements; $F 3$ is the sum of the factors that fractionalized the degree of each water quality variable for the standards. The KWQI ranges from 0 to 100, with a higher value representing cleaner water. In this assessment, KWQI values were divided into the following five grades: excellent (80-100), good (60-79), fair (40-59), poor (20-39), and very poor (0-19).

\section{Results And Discussion}

\subsection{PCA and FA}

The FA results obtained by conducting PCA and then rotating the result using the varimax method identified four VFs with an eigenvalue $\geq 1.0$, and the total variance was $72.18 \%$ (Table 1). VF1 represented $22.17 \%$ of the total variance, and COD and TOC showed a "strong" loading; and BOD, TSS, and Chl-a showed a "moderate" loading. VF2 accounted for $20.45 \%$ of the total variance, and DO and TP showed a "strong" loading; and WT, PO4-P, and FC showed a "moderate" loading. VF3 represented $18.43 \%$ of the total variance, and $\mathrm{TN}^{2}$ and $\mathrm{NH}_{3}-\mathrm{N}$ showed a "strong" loading; EC and $\mathrm{NO}_{3}-\mathrm{N}$ showed a "moderate" loading. VF4 accounted for $11.13 \%$ of the total variance, and pH showed a "strong" loading.

The principal factors (PFs) were expressed in a scatter plot using VF1 and VF2 in Fig. 2, which are factors that significantly affect the water quality of the river. BOD, Chl-a, TSS, TOC, and COD were extracted from PF1, while $\mathrm{FC}, \mathrm{PO}_{4}-\mathrm{P}, \mathrm{WT}$, and TP were extracted from PF2. As shown in Fig. 2, the major variables were found to be organic pollutants, substances related to metabolism in the river, phosphorus, and FC. As for organic pollutants, large amounts of non-biodegradable organic matter have been discharged due to recent rapid urban growth, industrialization, and intense human activities (Jung et al. 2015; Choi et al. 2017), implying that more stringent regulations for organic pollutants are required. In addition, for urban rivers that pass through metropolitan cities 
with large populations and high levels of industrialization, the appropriate operation of STFs and WTFs is required given the continuous discharges from certain pollution sources (Choi et al. 2016; Shin et al. 2018; Xu et al. 2019).

\subsection{Water quality assessment}

Descriptive statistics (Table 2) for the PF1 and PF2 variables of the PCA/FA results are compared with the environmental standards for rivers in Korea in Table 3. Based on the mean values for PF1, BOD was found to be "very good" and "slightly good" at sites S1 to S3, and "moderate" at sites S4 to S6; COD was "moderate" at sites S1 to S5 and "slightly bad" at site S6; TOC was "slightly good" at sites S1 to S3, "moderate" at sites S4 to S5, and "bad" at site S6. For BOD, COD, and TOC, which represent the levels of organic pollutants, water quality grades varied between each site. This is because biodegradable organic materials are currently more strictly regulated in STFs; however, regulation of household sewage in urban areas and the non-biodegradable organic matter generated in industrial complexes remains insufficient. In particular, it is assumed that high COD and TOC concentrations at site S6 reflect the large textile-dyeing complexes along the section of the river between sites S5 and S6, from which untreated non-biodegradable organic matter is discharged.

TSS was classified as "very good" at all the test sites, with concentrations of $\leq 25 \mathrm{mg} / \mathrm{L}$. During the flood season, the range and standard deviation of the TSS concentrations were high because of the inflows of large amounts of suspended solids. Although Chl-a is not included in the existing water quality standards, concentrations increased toward the downstream area of the river where pollution inflows are concentrated relative to upstream areas. Indeed, many of the nutrients introduced from STF effluents stimulate green algae growth in stagnant waters in the downstream section of the river, which also has negative effects on water quality.

Based on PF2, TP was found to be "very good" at sites S1 and S2 and "slightly good" at sites S3 to S6. TP is strictly managed based on the Korean Government's regulations on the concentrations of STF and WTF effluents (MOE 2009). However, continuous management is required along the Namcheon tributary, which flows into the river upstream of site $S 3$, as stables and vineyards are widespread in this area, which can act as nonpoint pollution sources during rainfall events. The $\mathrm{PO}_{4}-\mathrm{P}$ concentrations were similar to those of TP, and WT varied significantly over time owing to the strong seasonal effect of the monsoonal climate. FC concentrations were classified as "good" at sites S1 to S2 but were very high at sites S3 to S6, exceeding the current environmental standards (1,000 colony-forming unit (CFU)/100 mL < FC). The increase in FC concentrations in the downstream direction likely reflected the introduction of STF and WTF effluents from the metropolitan areas downstream of site S2.

When water quality was assessed by comparing the major variables extracted from the PCA and FA with the current environmental standards, overall water quality was poor in the downstream section of the river relative to the upstream section because of the significant influence of the point pollution sources located in the urban areas, most notably the STFs and WTFs. In addition, the water quality characteristics of the river were found to vary depending on the surrounding land-use patterns.

\subsection{Temporal and spatial cluster analysis}


The results of the $\mathrm{CA}$ and temporal and spatial classification using the water quality data of the monitoring sites (S1 to S6) are shown in Fig. 3. Based on the seasonal CA results (Fig. 3A), March to June was classified as "cluster1 (spring)," July to September as "cluster2 (summer)," October to December as "cluster3 (autumn)," and January to February as "cluster4 (winter)." These four distinct seasons reflect the mid-latitude temperate monsoonal climate of the study basin. The average total precipitation of the target watershed over the last ten years was $1,089.1 \mathrm{~mm}, 54.6 \%(594.8 \mathrm{~mm})$ of which fell between July and September. Due to this strong temporal rainfall bias, the flow of the river significantly varies between seasons, which is also assumed to result in seasonal water quality variations.

Based on the spatial CA results (Fig. 3B), sites S1 to S2 were classified as "cluster1 (upstream: US)," sites S3 to S5 as "cluster2 (middle stream: MS)," and site S6 as "cluster3 (downstream: DS)." These clusters correspond to the US section with relatively few pollution sources, the MS section with urban STFs, and the DS section with large industrial complexes, WTFs, and greenhouse facilities. These areas are more clearly distinguished from the land-use map of the Geumho River watershed (Fig. 4). Cluster1 corresponds to the area with a high proportion of forests and farmlands; cluster2 corresponds to urban areas with residential, commercial, and industrial land-cover types; and cluster 3 includes a complex mix of land uses.

\subsection{Temporal and spatial DA}

DA was conducted following the CA according to the pre-classified temporal and spatial water quality characteristics. Thus, temporal accuracy was maximized by conducting the DA according to the seasonal classification (spring, summer, autumn, and winter). DA was conducted in standard and stepwise modes, and the discriminant function and classification matrix constructed for each mode are shown in Tables 4 and 5 . In the standard mode, all 15 water quality variables were used, and the average accuracy of the classified matrix was as high as $80.2 \%$ (Table 5 ). In the stepwise mode, which reduces the number of variables relative to the standard mode, six water quality variables (WT, BOD, TOC, EC, $\mathrm{NH}_{3}-\mathrm{N}$, and TP) were used, yielding an accuracy of $78.8 \%$ (Table 5). Notably, in the stepwise mode, spring and autumn showed relatively low classification accuracies of $75.0 \%$ and $74.0 \%$, respectively.

To evaluate water quality according to the temporal classification, the six water quality variables identified based on the stepwise approach are shown in a box plot in Fig. 5, which confirmed the homogeneity of the groups based on the ANOVA results and the Scheffe Test $(p<0.05)$. WT was highest in summer and tended to fluctuate in line with seasonal changes. WT was more variable in spring and autumn than in summer and winter. BOD was highest and more variable in spring and tended to lower in summer and autumn, and increased again during winter. In contrast, TOC concentrations were highest in summer relative to the other seasons. BOD and TOC are representative organic pollution indicators, and the fluctuations in their concentrations likely reflect

the influence of increased river flows due to rainfall. In the case of EC, average values did not significantly differ between seasons, although there were seasonal differences in EC variability. $\mathrm{NH}_{3}-\mathrm{N}$ was recorded at significantly higher concentrations in winter than during the other seasons. This may reflect high $\mathrm{NH}_{3}-\mathrm{N}$ discharges from STFs and WTFs coupled with relatively low denitrification rates in winter when water temperatures are lower. In many countries, $\mathrm{NH}_{3}-\mathrm{N}$ is managed by setting water quality standards for rivers and the effluents from water treatment facilities (Han et al. 2015), yet in Korea, $\mathrm{NH}_{3}-\mathrm{N}$ is not regulated. This requires further consideration in the context of water quality management in Korea. For example, aquatic ammonia 
toxicity in rivers increases when the $\mathrm{NH}_{3}-\mathrm{N}$ concentrations rise above 1.0 and pH > 8.0 (Sawyer et al. 2003); in winter, the concentration of $\mathrm{NH}_{3}-\mathrm{N}$ in the Geumho River was > 1.0 (Fig. 5) and the average $\mathrm{pH}$ in the MS section was 8.5 (Fig. 6). These results may be problematic for aquatic life in this river (Mbuligwe and Kaseva 2005). In addition, inflows containing high concentrations of $\mathrm{NH}_{3}-\mathrm{N}$ have negative impacts on $\mathrm{BOD}$ and eutrophication in rivers (Han et al. 2015; Li et al. 2020). In the case of TP, average concentrations and ranges were much higher in summer than during the other seasons. This likely reflects the various nonpoint sources that contribute pollutants during the summer flood season as well as untreated effluents that exceed the capacity of the STFs during intense rainfall (i.e., storm overflow).

DA was also conducted based on the CA spatial classification (US, MS, and DS). The discriminant function and classification matrix of the results following the standard and stepwise modes are shown in Tables 6 and 7, respectively. In the standard mode, all 15 variables were used, and the average accuracy of the classified matrix was as high as $97.9 \%$ (Table 7). In the stepwise mode, seven variables (pH, BOD, COD, TOC, EC, TN, and TP) were used, yielding a classification accuracy of $92.0 \%$ (Table 7). Notably, the classification accuracy for US (89.6\%) was relatively low compared to other classification results in the stepwise mode, and the accuracies for MS and DS were 91.7 and $97.9 \%$, respectively.

To evaluate the water quality characteristics according to the spatial classification, the seven water quality variables identified based on the stepwise analysis are shown in Fig. 6, which confirms the homogeneity of the groups based on the ANOVA results and the Scheffe Test $(\mathrm{p}<0.05) . \mathrm{pH}, \mathrm{TN}$, and TP were high in the MS, which likely reflects nutrient inputs from the six STFs and WTFs located between sites S3 and S6 (Fig. 1). These inputs can stimulate phytoplankton growth, which can decrease oxygen saturation and increase carbon dioxide saturation in water, thereby increasing $\mathrm{pH}$ (Vajravelu et al., 2018). BOD, COD, TOC, and EC increased toward the DS section of the river compared to the US section, suggesting the inflow of organic pollutants in association with urbanization and industrialization in the DS area (see Fig. 4). TN and TP also showed similar trends, although average concentrations in the MS section were similar to the DS section, and variability was higher in the MS section than in the DS section. These patterns may reflect the high proportion of farmland in the MS section relative to the DS section, which acts as a nonpoint pollution source during certain conditions. For the purpose of creating an urban landscape, the amount of water through river dredging increased. However, the flow of the river decreased and stagnant water formed. This reduction in the self-purification capacity of the river has an adverse effect on water quality. In addition, as a result of reductions in the flow during the dry season, effluents from the STFs and WTFs typically make up the majority of instream flow (Yang and Bae 2012). The treatment facilities in the Geumho River Basin treat both domestic wastewater and industrial effluents, which can contain non-biodegradable organic matter, and requires ongoing regulation and management (Choi et al. 2017).

\subsection{Water quality assessment using the KWQI}

The water quality of the river was assessed for each temporally and spatially classified group using seven water quality variables applied by the Korean Ministry of Environment (pH, DO, EC, WT, TOC, TN, and TP) (Table 8 and Fig. 7). For the seasonal groups, KWQI values ranged from 55.2 to 61.6 in spring, from 58.4 to 70.1 in summer, from 60.4 to 66.3 in autumn, and from 67.7 to 75.1 in winter. In addition, the average KWQI values for 
these seasons across the four-year study period were 59.2, 63.4, 63.1, and 70.9, respectively. The average KWQI value was lowest in spring (59.2), falling below 60 during the 2017-2018 period.

For spatial groups, KWQI values ranged from 64.4 to 69.0 in the US section, from 53.3 to 59.8 in the MS section, and from 60.3 to 66.6 in the DS section. In addition, the average KWQI values for these sections across the fourear study period were 67.5, 56.4, and 62.5, respectively. The Korean Ministry of Environment considers that there is a pollutant inflow problem when the KWQI $\leq 60$ (NIER 2013). The MS group showed the lowest average KWQI value (56.4), indicating that intensive water quality management measures are required in this section of the river. The KWQI evaluation also showed that pollution was greatest during seasons when instream flows were low and in those sections where multiple treatment facilities are located, which is consistent with the results discussed in Section 3.4.

\section{Conclusion}

Major water quality variables for the Geumho River were temporally and spatially classified and analyzed using various statistical analyses. Among the variables extracted from the PCA and FA, COD, TOC, TP, and TSS exhibited very strong loadings, indicating that non-biodegradable organic matter and nonpoint sources generated during rainfall are the main causes of water quality deterioration in the study basin. Based on the temporal (spring, summer, autumn, and winter) and spatial (US, MS, DS) classifications, water quality dynamics during the study period were evaluated and countermeasures were identified. Based on the KWQI, the overall water quality classification for the study river is "good", although this drops to "fair" during some seasons and in some sections. The poorest water quality occurs in spring (average KWQI $=59.2$ ) and in the MS section (average KWQI $=56.4$ ).

Given the critical importance of rivers for human life, including the roles in leisure activities and industrial activities, efficient water quality management is required to minimize negative impacts on human and environmental health. Based on the results obtained in this study, future research and monitoring should target those seasons and river sections identified as having the lowest water quality, i.e., the spring season and the MS and DS river sections.

\section{Declarations}

Ethics approval and consent to participate: Not applicable.

Consent for publication: Not applicable.

Availability of data and materials: The datasets used and/or analyzed during the current study are available from the corresponding author upon reasonable request.

Competing interests: The authors declare that they have no conflicts of interest.

Funding: This work was supported by the National Institute of Environmental Research (NIER), funded by the Ministry of Environment (MOE) of the Republic of Korea [grant number NIER-2021-01-01-042]. The funding agency had no role in study design; in the collection, analysis, and interpretation of data; in the writing of the report; and in the decision to submit the article for publication. 
Authors' contributions: All authors contributed to the planning and structuring of the study. C.D. Jo: manuscript writing, data analysis, and visualization. J.M. Kim: data collection and investigation. S.M. Kim: data collection and investigation. H.G. Kwon: manuscript review and editing.

Acknowledgments: We thank the anonymous reviewers for their comments on improving the manuscript. We also thank the members of the Nakdong River Environmental Research Center for their assistance.

\section{References}

Azhar SC, Aris AZ, Yusoff MK, Ramli MF, Juahir H (2015) Classification of river water quality using multivariate analysis. Procedia Environ Sci 30:79-84.

Barakat A, Baghdadi ME, Rais J, Aghezzaf B, Slassi M (2016) Assessment of spatial and seasonal water quality variation of Oum Er Rbia River (Morocco) using multivariate statistical techniques. Int Soil Water Conser Res 4:284-292.

Chai Y, Xiao C, Li M, Liang X (2020) Hydrogeochemical characteristics and groundwater quality evaluation based on multivariate statistical analysis. Water 12:2792.

Choi BD (2004) The function or urban river and sustainable reginal development: The case of Kumho River. J Korean Assoc Regional Geographers 10:757-774.

Choi YY, Baek SR, Kim JI, Choi JW, Hur J, Lee TU, Lee BJ (2017) Characteristics and biodegradability of wastewater organic matter in municipal wastewater treatment plants collecting domestic wastewater and industrial discharge. Water 9:409.

Dominick D, Juahir H, Latif MT, Zain SM (2012). Spatial assessment of air quality patterns in Malaysia using multivariate analysis. Atmosph Environ 60:172-181.

Fan X, Cui B, Zhao H, Zhang Z, Zhang H (2010) Assessment of river water quality in Pearl River Delta using multivariate statistical techniques. Procedia Environ Sci 2:1220-1234.

Gurjar SK, Tare V (2019) Spatial-temporal assessment of water quality and assimilative capacity of river Ramganga, a tributary of Ganga using multivariate analysis and QUEL2K. J Clean Prod 222:550-564.

Han SH, Kim YY, Sung YG, Park IB, Cho DH, Nam WK, Kim CG, Oh JK (2015) Characteristics of organics and ammonia nitrogen discharged by pollution source from human living. J Korean Soc Water Environ 31:377-386.

Jung KY, Ahn JM, Lee KL, Lee IJ, Yu JJ, Cheon SU, Kim KS, Han KY (2015) Temporal and spatial analysis of non-biodegradable organic pollutants in the Geumho River system. J Environ Sci Int 24:1343-1362.

Jung KY, Lee IJ, Lee KL, Cheon SU, Hong JY, Ahn JM (2016) Long-term trend analysis and exploratory data analysis of Geumho River based on seasonal Mann-Kendall test. J Environ Sci Int 25:217-229.

Kwak IS, Choi BR, Jeon HR, Kim SA, Bae JY, Kim S, Kim JM (2020) Analysis of water quality improvement effect by securing water quality characteristics and flow rate in the Geumho River. J Environ Impact Assess 29:414429. 
Li D, Huang D, Guo C, Guo X (2015) Multivariate statistical analysis of temporal-spatial variations in water quality of a constructed wetland purification system in a typical park in Bejing, China. Environ Monitor Assess 187:4219.

Li T, Li S, Liang C, Bush RT, Xiong L, Jiang Y (2018) A comparative assessment of Australia's Lower Lakes water quality under extreme drought and post-drought conditions using multivariate statistical techniques. J Cleaner Prod 190:1-11.

Li X, Lu MY, Huang Y, Yuan Y, Yuan Y (2020) Influence of seasonal temperature change on autotrophic nitrogen removal for mature landfill leachate treatment with high-ammonia by partial nitrification-Anammox process. $J$ Environ Sci 102:291-300.

Liu CW, Lin KH, Kuo YM (2003) Application of factor analysis in the assessment of ground water quality in a blackfoot disease area in Taiwan. Sci Total Environ 313:77-89.

Liu L, Dong Y, Kong M, Zhou J, Zhao H, Tang Z, Zhang M, Wang Z (2020) Insights into the long-term pollution trends and sources contributions in Lake Taihu, China using multi-statistic analyses models. Chemosphere 242:125272.

Mbuligwe SE, Kaseva ME (2005) Pollution and self-cleansing of an urban river in a developing country: a case study in Dar es Salaam. Tanzania. Environ Manage 36:328-342.

MOE (2000) Yesterday, today, and future of the Geumho River. Ministry of Environment, Sejong.

MOE (2005) Geumho River alive. Ministry of Environment, Sejong.

MOE (2008) Official test method for water pollution. Ministry of Environment, Sejong.

MOE (2009) Basic Policy for Total maximum daily loads in Nakdong River. Ministry of Environment, Sejong.

MOE (2019a) Framework act on environmental policy. Ministry of Environment, Sejong.

MOE (2019b) Sewerage statistics. Ministry of Environment, Sejong.

NIER (2013) Real time water quality data system construction and database enhancement. National Institute of Environmental Research, Incheon.

Nkomozepi T, and Chung SO (2014) The effects of climate change on the water resources of the Geumho River basin, Republic of Korea. J Hydro-environ Res 8:358-366.

Nong X, Shao D, Zhong H, Liang J (2020) Evaluation of water quality in the South-to-North Water Diversion Project of China using the water quality index (WQI) method. Water Res 178:115781.

Park JH, Park BK, Lee JK, Rhew DH (2013) Necessity of refractory organic matter management in total maximum daily loads (TMDLs). J Korean Soc Water Environ 29:393-399.

Park KO, Lee CH, Cha IG (2016) Water pollution source tracing using FDC and correlation analysis in Geumho River basin. J Wetlands Res 18:232-243. 
Ren J, Liang J, Ren B, Zheng X, Guo C (2018) New patterns of temporal and spatial variation in water quality of a highly artificialized urban river-course-A case study in the Tongzhou section of the Beiyun

River. Water 10:1446.

Rogerson PA (2019) Statistical methods for geography: a student's guide. Sage Publications, London.

Salla MR, Ferreira AM, Pereira CE, Schmidt MAR (2014) Self-cleaning ability of middle and lower courses of the Uberaba River, Upgrh-GD8. J Urban Environ Engin 8:118-133.

Sarbu C, Pop HF (2005) Principal component analysis versus fuzzy principal component analysis A case study: the quality of Danube water (1985-1996). Talanta 65, 1215-1220.

Sawyer CN, McCarty PL, Parkin GF (2003) Chemistry for environmental engineering and science. McGraw-Hill, New York.

Shin SH, Im TH, Kim SH, Shin DS, Kwon HG (2018) Consideration in applying Korean-comprehensive water quality index (K-CWQI) to assessement of water quality in the major tributaries of Gumho-River Basin. Korean Soc Hazard Mitigation 18:455-465.

Shrestha S, Kazama F (2007) Assessment of surface water quality using multivariate statistical techniques: A case study of the Fuji river basin, Japan. Environ Model Software 22:464-475.

Tian Y, Jiang Y, Liu Q, Dong M, Xu D, Liu Y, Xu X (2019) Using a water quality index to assess the water quality of the upper and middle streams of the Luanhe River, northern China. Sci Total Environ 667:142-151.

Ustaoğlu F, Tepe Y, Taş B (2020) Assessment of stream quality and health risk in a subtropical Turkey river system: A combined approach using statistical analysis and water quality index. Ecol Indicators 113:105815.

Vajravelu M, Martin Y, Ayyappan S, Mayakrishnan M (2018) Seasonal influence of physico-chemical parameters on phytoplankton diversity, community structure and abundance at Parangipettai coastal waters, Bay of Bengal, South East Coast of India. Oceanologia 60:114-127.

Varol M (2020) Spatio-temporal changes in surface water quality and sediment phosphorus content of a large reservoir in Turkey. Environ Pollution 259:113860.

Wen Y, Schoups G, Giesen NV (2017) Organic pollution of rivers: Combined threats of urbanization, livestock farming and global climate change. Sci Rep 7:1-9.

Wu Z, Wang X, Chen Y, Cai Y, Deng J (2018) Assessing river water quality using water quality index in Lake Taihu Basin, China. Sci Total Environ 612:914-922.

Xu Z, Xu J, Yin H, Jin W, Li H, He Z (2019) Urban river pollution control in developing countries. Nat Sustainability 2:158-160.

Yang DS, Bae HK (2012) The effect of branches on Kumho River's water quality. Journal Environ Sci Int 21:1245-1253. 
Yang S, Liang M, Qin Z, Qian Y, Li M, Cao Y (2021) A novel assessment considering spatial and temporal variations of water quality to identify pollution sources in urban rivers. Sci Rep 11:1-11.

Zeinalzadeh K, Rezaei E (2017) Determining spatial and temporal changes of surface water quality using principal component analysis. J Hydrol: Regional Studies 13:1-10.

Zhang Q, Li Z, Zeng G, Li J, Fang Y, Yuan Q, Wang Y, Ye F (2009) Assessment of surface water quality using multivariate statistical techniques in red soil hilly region: a case study of Xiangjiang watershed, China. Environ Monitor Assess 152:123-131.

\section{Tables}

Table 1. Variable loads for the major components of all data based on principal component analysis (PCA) and factor analysis (FA).

\begin{tabular}{|c|c|c|c|c|}
\hline \multirow[t]{2}{*}{ Variable } & \multicolumn{4}{|c|}{ Component } \\
\hline & VF1 & VF2 & VF3 & VF4 \\
\hline WT & 0.242 & 0.729 & -0.377 & 0.316 \\
\hline $\mathrm{pH}$ & 0.062 & -0.019 & -0.018 & 0.787 \\
\hline DO & 0.009 & -0.784 & 0.188 & -0.288 \\
\hline BOD & 0.606 & 0.068 & 0.324 & 0.474 \\
\hline COD & 0.928 & 0.035 & -0.071 & -0.005 \\
\hline TOC & 0.864 & 0.167 & 0.111 & -0.008 \\
\hline TSS & 0.692 & 0.428 & -0.044 & -0.153 \\
\hline EC & 0.429 & -0.104 & 0.708 & 0.174 \\
\hline TN & -0.066 & 0.201 & 0.873 & 0.157 \\
\hline $\mathrm{NH}_{3}-\mathrm{N}$ & 0.007 & 0.047 & 0.854 & -0.032 \\
\hline $\mathrm{NO}_{3}-\mathrm{N}$ & 0.070 & -0.312 & 0.604 & -0.186 \\
\hline TP & 0.265 & 0.835 & 0.221 & -0.01 \\
\hline $\mathrm{PO}_{4}-\mathrm{P}$ & 0.111 & 0.656 & -0.084 & -0.484 \\
\hline Chl-a & 0.721 & 0.144 & 0.156 & 0.489 \\
\hline $\mathrm{FC}$ & 0.116 & 0.636 & 0.156 & -0.235 \\
\hline Eigenvalue & 3.326 & 3.068 & 2.764 & 1.669 \\
\hline Total variance (\%) & 22.17 & 20.45 & 18.43 & 11.13 \\
\hline Cumulative variance (\%) & 22.17 & 42.62 & 61.05 & 72.18 \\
\hline
\end{tabular}


$\mathrm{KMO}$ test $=0.736$ and Bartlett's test $=0.000$, indicating that the data were suitable for PCA/FA and that there was a significant relationship between the variables.

Bold and italic values represent strong and moderate loadings, respectively.

VF, varifactor; WT, water temperature; DO, dissolved oxygen; BOD, biochemical oxygen demand; COD, chemical oxygen demand; TOC, total organic carbon; TSS, total suspended solids; EC, electrical conductivity; TN, total nitrogen; $\mathrm{NH}_{3}-\mathrm{N}$, ammonia-nitrogen; $\mathrm{NO}_{3}-\mathrm{N}$, nitrate-nitrogen; $\mathrm{PO}_{4}-\mathrm{P}$, phosphate-phosphorus; $\mathrm{TP}$, total phosphorus; Chl-a, chlorophyll-a; FC, fecal coliform.

Table 2. Range, mean, and standard deviation for variables at the water quality monitoring sites. 


\begin{tabular}{|c|c|c|c|c|c|c|c|}
\hline Parameter & & $S 1(n=48)$ & $S 2(n=48)$ & S3 $(n=48)$ & $\mathrm{S} 4(\mathrm{n}=48)$ & S5 $(n=48)$ & $S 6(n=48)$ \\
\hline \multirow[t]{2}{*}{$\mathrm{BOD}(\mathrm{mg} / \mathrm{L})$} & $\mathrm{R}$ & $0.3-5.9$ & $0.5-5.8$ & $1.1-5.0$ & $0.9-6.2$ & $1.0-5.7$ & $1.0-5.7$ \\
\hline & $\begin{array}{l}M \\
\pm \\
S D\end{array}$ & $1.0 \pm 0.8$ & $2.1 \pm 1.3$ & $2.4 \pm 0.9$ & $3.0 \pm 1.5$ & $3.1 \pm 1.3$ & $3.0 \pm 1.3$ \\
\hline \multirow[t]{2}{*}{$\mathrm{COD}(\mathrm{mg} / \mathrm{L})$} & $\mathrm{R}$ & $3.0-7.8$ & $3.8-10.3$ & $4.3-8.6$ & $4.3-9.2$ & $4.0-9.8$ & $5.8-11.2$ \\
\hline & $\begin{array}{l}M \\
\pm \\
\text { SD }\end{array}$ & $5.6 \pm 1.0$ & $6.7 \pm 1.4$ & $5.7 \pm 0.9$ & $5.9 \pm 1.2$ & $5.9 \pm 1.4$ & $8.2 \pm 1.5$ \\
\hline \multirow[t]{2}{*}{ TOC (mg/L) } & $\mathrm{R}$ & $1.7-4.7$ & $2.3-5.4$ & $2.6-5.9$ & $2.5-6.1$ & $2.5-5.8$ & $4.7-8.9$ \\
\hline & $\begin{array}{l}M \\
\pm \\
S D\end{array}$ & $3.4 \pm 0.6$ & $3.8 \pm 0.7$ & $3.9 \pm 0.7$ & $4.1 \pm 0.8$ & $4 \pm 0.8$ & $6.3 \pm 1.2$ \\
\hline \multirow[t]{2}{*}{ TSS (mg/L) } & $\mathrm{R}$ & $0.6-13.4$ & $0.4-23.6$ & $1.4-32.8$ & $1.8-24.2$ & $1.4-26.7$ & $2.6-55.0$ \\
\hline & $\begin{array}{l}M \\
\pm \\
\text { SD }\end{array}$ & $3.3 \pm 3.0$ & $6.4 \pm 5.0$ & $4.4 \pm 4.5$ & $5.0 \pm 3.6$ & $8.6 \pm 5.5$ & $10.3 \pm 8.3$ \\
\hline \multirow[t]{2}{*}{ Chl-a $(\mathrm{mg} / \mathbb{\mathbb { Z }})$} & $\mathrm{R}$ & $0.2-18.4$ & $1.9-45.9$ & $2.8-37.1$ & $2.3-78.6$ & $2.8-96.7$ & $6.7-135.8$ \\
\hline & $\begin{array}{l}M \\
\pm \\
\text { SD }\end{array}$ & $4.4 \pm 3.0$ & $10.3 \pm 8.2$ & $11.5 \pm 9.9$ & $25.0 \pm 20.6$ & $27.6 \pm 20.9$ & $36.3 \pm 26.2$ \\
\hline \multirow[t]{2}{*}{$\mathrm{TP}(\mathrm{mg} / \mathrm{L})$} & $\mathrm{R}$ & $\begin{array}{l}0.01- \\
0.08\end{array}$ & $\begin{array}{l}0.01- \\
0.18\end{array}$ & $0.02-0.19$ & $0.02-0.16$ & $0.02-0.18$ & $0.03-0.13$ \\
\hline & $\begin{array}{l}M \\
\pm \\
\text { SD }\end{array}$ & $0.02 \pm 0.01$ & $0.04 \pm 0.03$ & $0.07 \pm 0.04$ & $0.07 \pm 0.04$ & $0.08 \pm 0.04$ & $0.07 \pm 0.03$ \\
\hline \multirow[t]{2}{*}{$\mathrm{PO}_{4}-\mathrm{P}(\mathrm{mg} / \mathrm{L})$} & $\mathrm{R}$ & $\begin{array}{l}0.00- \\
0.07\end{array}$ & $\begin{array}{l}0.00- \\
0.09\end{array}$ & $0.00-0.11$ & $0.00-0.12$ & $0.00-0.1$ & $0.00-0.1$ \\
\hline & $\begin{array}{l}M \\
\pm \\
\text { SD }\end{array}$ & $0.01 \pm 0.01$ & $0.02 \pm 0.03$ & $0.02 \pm 0.03$ & $0.01 \pm 0.03$ & $0.01 \pm 0.03$ & $0.02 \pm 0.03$ \\
\hline \multirow[t]{2}{*}{ WT $\left({ }^{\circ} \mathrm{C}\right)$} & $\mathrm{R}$ & $3.2-27.6$ & $3.8-30.5$ & $0.8-30.5$ & $2.2-31.9$ & $3.6-31.6$ & $5.1-29.4$ \\
\hline & $\begin{array}{l}M \\
\pm \\
\text { SD }\end{array}$ & $14.7 \pm 6.8$ & $17.0 \pm 8.2$ & $16.8 \pm 8.8$ & $17.5 \pm 8.9$ & $18.1 \pm 8.6$ & $17.4 \pm 7.9$ \\
\hline \multirow[t]{2}{*}{$\begin{array}{l}\text { FC } \\
\text { (CFU/100mL) }\end{array}$} & $\mathrm{R}$ & $0-165$ & $0-560$ & $0-48000$ & $0-20000$ & $0-57000$ & $3-28963$ \\
\hline & $\begin{array}{l}M \\
\pm \\
\text { SD }\end{array}$ & $22 \pm 40$ & $65 \pm 133$ & $4137 \pm 8789$ & $2143 \pm 4459$ & $5559 \pm 11989$ & $4224 \pm 6497$ \\
\hline
\end{tabular}


S1 to S6, monitoring sites; R, range; $M$, mean; SD, standard deviation; BOD, biochemical oxygen demand; COD, chemical oxygen demand; TOC, total organic carbon; TSS, total suspended solids; Chl-a, chlorophyll- $a$; TP, total phosphorus; $\mathrm{PO}_{4}-\mathrm{P}$, phosphate-phosphorus; $\mathrm{WT}$, water temperature; $\mathrm{FC}$, fecal coliform; $\mathrm{CFU}$, colony forming unit.

Table 3. Environmental standards for river water quality in Korea (MOE, 2019a).

\begin{tabular}{|c|c|c|c|c|c|c|}
\hline Grade & $\begin{array}{l}\text { BOD } \\
(\mathrm{mg} / \mathrm{L})\end{array}$ & $\begin{array}{l}\text { COD } \\
(\mathrm{mg} / \mathrm{L})\end{array}$ & $\begin{array}{l}\text { TOC } \\
(\mathrm{mg} / \mathrm{L})\end{array}$ & $\begin{array}{l}\text { TSS } \\
(\mathrm{mg} / \mathrm{L})\end{array}$ & $\begin{array}{l}\text { TP } \\
(\mathrm{mg} / \mathrm{L})\end{array}$ & $\begin{array}{l}\mathrm{FC} \\
(\mathrm{CFU} / 100 \mathrm{~mL})\end{array}$ \\
\hline Very good & 1.0 or less & 2.0 or less & 2.0 or less & 25 or less & 0.02 or less & 10 or less \\
\hline Good & $1.0-2.0$ & $2.0-4.0$ & $2.0-3.0$ & 25 or less & $0.02-0.04$ & $10-100$ \\
\hline Slightly good & $2.0-3.0$ & $4.0-5.0$ & $3.0-4.0$ & 25 or less & $0.04-0.1$ & $100-200$ \\
\hline Moderate & $3.0-5.0$ & $5.0-7.0$ & $4.0-5.0$ & 25 or less & $0.1-0.2$ & $200-1,000$ \\
\hline Slightly bad & $5.0-8.0$ & $7.0-9.0$ & $5.0-6.0$ & 100 or more & $0.2-0.3$ & - \\
\hline Bad & $8.0-10.0$ & $9.0-11.0$ & $6.0-8.0$ & - & $0.3-0.5$ & - \\
\hline Very bad & Over 10.0 & Over 11.0 & Over 8.0 & - & Over 0.5 & - \\
\hline
\end{tabular}

BOD, biochemical oxygen demand; COD, chemical oxygen demand; TOC, total organic carbon; TSS, total suspended solids; TP, total phosphorus; FC, fecal coliform; CFU, colony-forming unit.

Table 4. Discriminant functions to determine temporal changes (Fisher's linear discriminant functions). 


\begin{tabular}{|c|c|c|c|c|c|c|c|c|}
\hline \multirow[t]{2}{*}{ Variable } & \multicolumn{4}{|c|}{ Standard mode } & \multicolumn{4}{|c|}{ Stepwise mode } \\
\hline & Spring & Summer & Autumn & Winter & Spring & Summer & Autumn & Winter \\
\hline WT & 1.403 & 1.835 & 1.245 & 0.832 & 0.839 & 1.153 & 0.618 & 0.24 \\
\hline $\mathrm{pH}$ & 30.538 & 29.493 & 30.018 & 30.593 & & & & \\
\hline DO & 4.33 & 4.58 & 4.534 & 4.707 & & & & \\
\hline BOD & -0.539 & -1.394 & -1.974 & -2.142 & 0.918 & -0.156 & -0.334 & -0.257 \\
\hline COD & 4.336 & 4.012 & 3.849 & 4.315 & & & & \\
\hline TOC & 3.706 & 3.533 & 2.887 & 3.138 & 2.63 & 2.639 & 1.93 & 2.402 \\
\hline TSS & -0.28 & -0.306 & -0.199 & -0.309 & & & & \\
\hline EC & -0.023 & -0.024 & -0.015 & -0.018 & -0.004 & -0.005 & 0.004 & 0.001 \\
\hline $\mathrm{TN}$ & 0.977 & 0.838 & 0.956 & 0.978 & & & & \\
\hline $\mathrm{NH}_{3}-\mathrm{N}$ & 2.342 & 2.842 & 2.574 & 2.226 & 5.91 & 6.678 & 3.798 & 12.755 \\
\hline $\mathrm{NO}_{3}-\mathrm{N}$ & 11.22 & 11.992 & 9.251 & 18.392 & & & & \\
\hline TP & 10.849 & 30.924 & 7.444 & 37.27 & -26.276 & 17.998 & -15.883 & -8.094 \\
\hline $\mathrm{PO}_{4}-\mathrm{P}$ & 23.452 & 62.642 & 41.274 & 38.946 & & & & \\
\hline Chl-a & -0.467 & -0.436 & -0.425 & -0.415 & & & & \\
\hline $\mathrm{FC}$ & 0.000 & 0.000 & 0.000 & 0.000 & & & & \\
\hline (Constant) & -183.986 & -185.44 & -174.56 & -181.562 & -15.585 & -22.645 & -9.746 & -9.174 \\
\hline
\end{tabular}

Spring, March-June; summer, July-September; autumn, October-December; winter, January-February; WT, water temperature; DO, dissolved oxygen; BOD, biochemical oxygen demand; $\mathrm{COD}$, chemical oxygen demand; TOC, total organic carbon; TSS, total suspended solids; EC, electrical conductivity; TN, total nitrogen; $\mathrm{NH}_{3}-\mathrm{N}$, ammonia-nitrogen; $\mathrm{NO}_{3}-\mathrm{N}$, nitrate-nitrogen; $\mathrm{PO}_{4}-\mathrm{P}$, phosphate-phosphorus; TP, total phosphorus; Chl-a, chlorophyll-a; FC, fecal coliform.

Table 5. Classification matrix for the discriminant analysis of temporal changes. 


\begin{tabular}{|c|c|c|c|c|c|c|c|}
\hline & \multirow[t]{2}{*}{ Monitoring clusters } & \multirow[t]{2}{*}{ Correct (\%) } & \multicolumn{5}{|c|}{ Regions assigned by DA } \\
\hline & & & Spring & Summer & Autumn & Winter & Total \\
\hline \multirow[t]{5}{*}{ Standard mode } & Spring & 76.0 & 73 & 6 & 12 & 5 & 96 \\
\hline & Summer & 87.6 & 7 & 63 & 2 & 0 & 72 \\
\hline & Autumn & 72.2 & 9 & 4 & 52 & 7 & 72 \\
\hline & Winter & 89.6 & 1 & 0 & 4 & 43 & 48 \\
\hline & Total & 80.2 & & & & & \\
\hline \multirow[t]{5}{*}{ Stepwise mode } & Spring & 74.0 & 71 & 9 & 13 & 3 & 96 \\
\hline & Summer & 81.9 & 12 & 59 & 1 & 0 & 72 \\
\hline & Autumn & 75.0 & 9 & 4 & 54 & 5 & 72 \\
\hline & Winter & 89.6 & 0 & 0 & 5 & 43 & 48 \\
\hline & Total & 78.8 & & & & & \\
\hline
\end{tabular}

Spring, March to June; summer, July to September; autumn, October to December; winter, January to February; DA, discriminant analysis

Table 6. Discriminant functions to determine spatial changes (Fisher's linear discriminant functions). 


\begin{tabular}{|c|c|c|c|c|c|c|}
\hline \multirow[t]{2}{*}{ Variable } & \multicolumn{3}{|c|}{ Standard mode } & \multicolumn{3}{|c|}{ Stepwise mode } \\
\hline & US & MS & DS & US & DS & \\
\hline WT & 1.174 & 0.868 & 0.908 & & & \\
\hline $\mathrm{pH}$ & 31.435 & 34.117 & 29.45 & 30.331 & 32.07 & 28.173 \\
\hline DO & 4.516 & 3.268 & 3.639 & & & \\
\hline BOD & -2.012 & -1.379 & -2.893 & -4.808 & -4.121 & -5.55 \\
\hline COD & 3.587 & 1.51 & 1.918 & 2.926 & 0.933 & 1.163 \\
\hline TOC & 1.177 & 2.96 & 7.835 & 0.065 & 1.552 & 6.727 \\
\hline TSS & -0.168 & -0.16 & -0.231 & & & \\
\hline EC & -0.021 & -0.011 & 0.016 & -0.004 & 0.009 & 0.032 \\
\hline TN & 1.042 & 1.394 & 1.097 & 2.234 & 2.802 & 2.575 \\
\hline $\mathrm{NH}_{3}-\mathrm{N}$ & 2.467 & 3.275 & 3.911 & & & \\
\hline $\mathrm{NO}_{3}-\mathrm{N}$ & 11.52 & 14.103 & 8.392 & & & \\
\hline TP & 38.524 & 103.418 & 17.876 & 69.724 & 131.491 & 98.784 \\
\hline $\mathrm{PO}_{4}-\mathrm{P}$ & 25.941 & 17.324 & 92.628 & & & \\
\hline Chl-a & -0.438 & -0.396 & -0.305 & & & \\
\hline FC & 0.000 & 0.000 & 0.000 & & & \\
\hline (Constant) & -176.379 & -186.667 & -189.161 & -132.62 & -151.867 & -153.374 \\
\hline
\end{tabular}

US, upstream (S1 to S2 site); MS, middle stream (S3 to S5 site); DS, downstream (S6 site); WT, water temperature; DO, dissolved oxygen; BOD, biochemical oxygen demand; COD, chemical oxygen demand; TOC, total organic carbon; TSS, total suspended solids; EC, electrical conductivity; TN, total nitrogen; $\mathrm{NH}_{3}-\mathrm{N}$, ammonia-nitrogen; $\mathrm{NO}_{3}-\mathrm{N}$, nitrate-nitrogen; $\mathrm{PO}_{4}-\mathrm{P}$, phosphate-phosphorus; TP, total phosphorus; Chl-a, chlorophyll-a; FC, fecal coliform.

Table 7. Classification matrix for the discriminant analysis of spatial changes. 


\begin{tabular}{lllllll} 
Period & Monitoring clusters & Correct (\%) & \multicolumn{5}{c}{ Regions assigned by DA } \\
\hline \multirow{2}{*}{ Standard mode } & & & US & MS & DS & Total \\
\hline & US & 96.9 & 93 & 3 & 0 & 96 \\
& MS & 97.9 & 3 & 141 & 0 & 144 \\
\hline & DS & 100 & 0 & 0 & 48 & 48 \\
\hline & Total & 97.9 & & & & \\
\hline Stepwise mode & US & 89.6 & 86 & 10 & 0 & 96 \\
\hline & MS & 91.7 & 8 & 132 & 4 & 144 \\
\hline & DS & 97.9 & 0 & 1 & 47 & 48 \\
\hline & Total & 92.0 & & & &
\end{tabular}

US, upstream (S1 to S2 site); MS, middle stream (S3 to S5 site); DS, downstream (S6 site); DA, discriminant analysis.

Table 8. Seasonal and spatial WQI scores during the research period.

\begin{tabular}{llllllll} 
Year & \multicolumn{2}{l}{ Seasonal } & \multicolumn{5}{c}{ Spatial } \\
\hline & Spring & Summer & Autumn & Winter & US & MS & DS \\
\hline 2017 & $\mathbf{5 5 . 2}$ & 60.8 & 60.4 & 75.1 & 64.4 & $\mathbf{5 8 . 9}$ & 60.3 \\
\hline 2018 & $\mathbf{5 9 . 9}$ & 64.2 & 66.3 & 67.7 & 68.3 & $\mathbf{5 3 . 5}$ & 61.6 \\
\hline 2019 & 60.1 & $\mathbf{5 8 . 4}$ & 60.4 & 70.3 & 68.5 & $\mathbf{5 3 . 3}$ & 61.4 \\
\hline 2020 & 61.6 & 70.1 & 65.6 & 70.6 & 69.0 & $\mathbf{5 9 . 8}$ & 66.6 \\
\hline Mean & $\mathbf{5 9 . 2}$ & 63.4 & 63.1 & 70.9 & 67.5 & $\mathbf{5 6 . 4}$ & 62.5
\end{tabular}

WQI scores at the "Fair" grade $(<60)$ are shown in bold.

Spring, March to June; summer, July to September; autumn, October to December; winter, January to February; US, upstream (S1 to S2 site); MS, middle stream (S3 to S5 site); DS, downstream (S6 site).

\section{Figures}




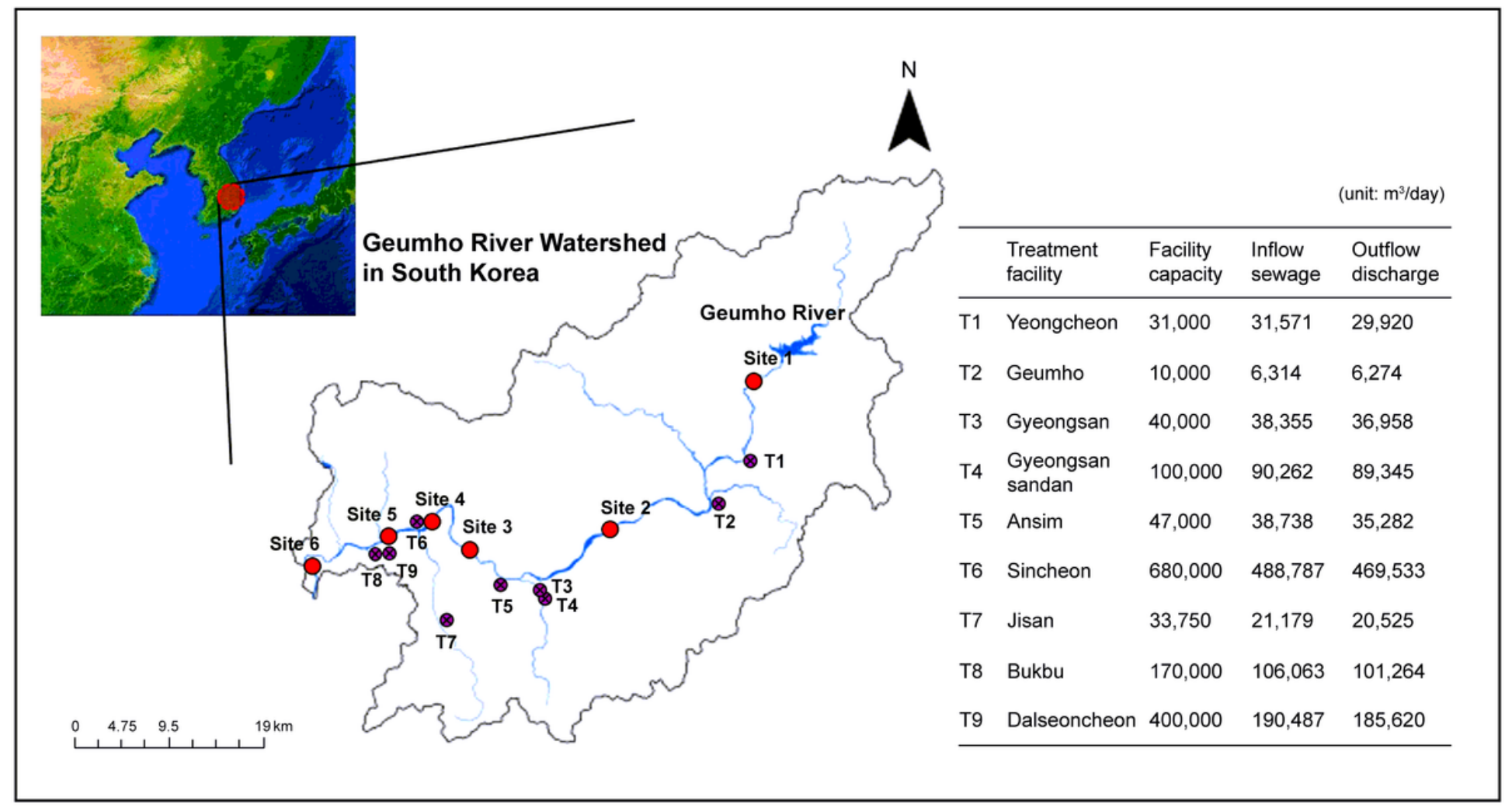

\section{Figure 1}

Locations of water monitoring sites and sewage and wastewater treatment facilities in the target watershed (MOE, 2019b). Red point, monitoring sites (S1 to S6); purple point, sewage and wastewater treatment facilities (T1 to T9) 


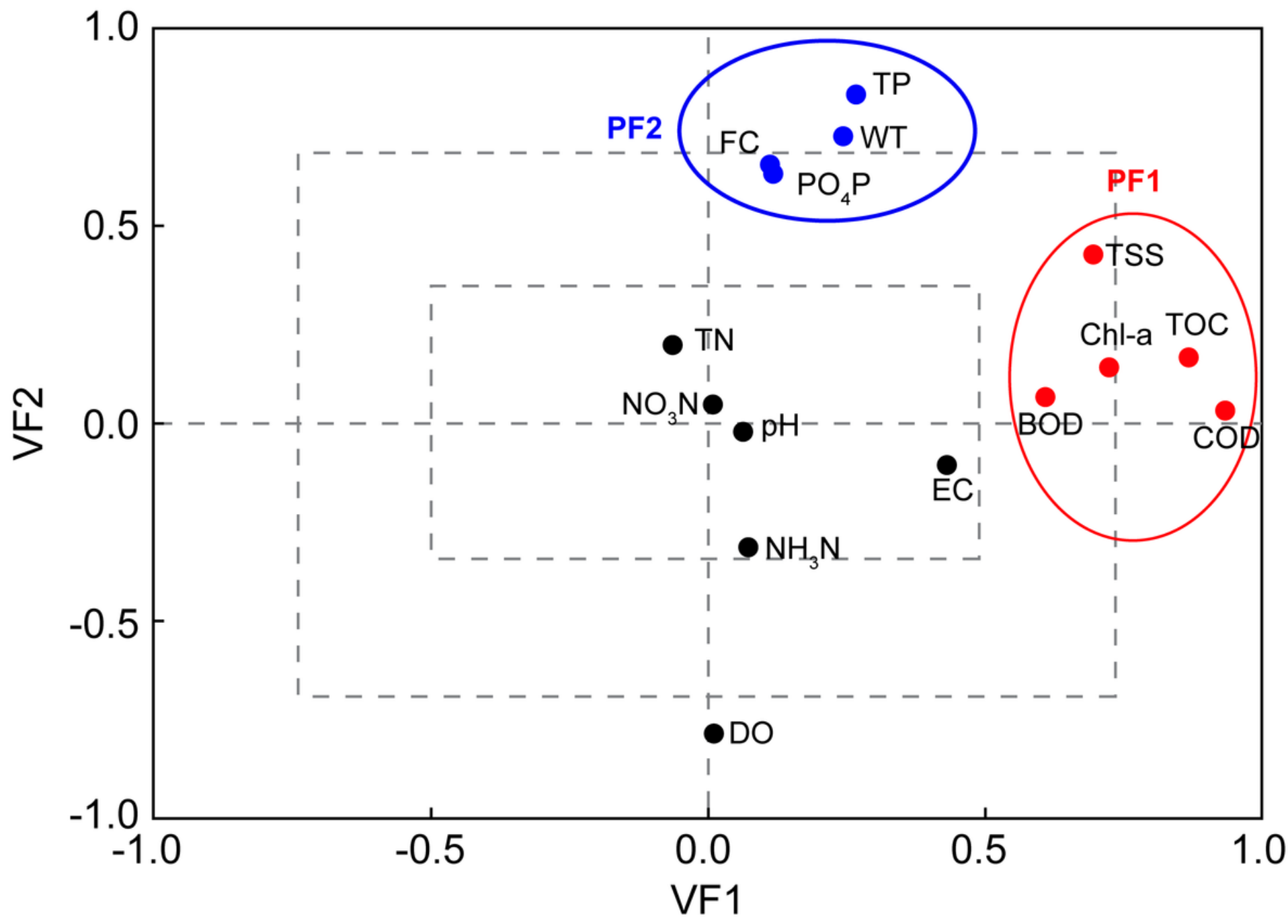

Figure 2

Major factors through the scatter plot of VF1 and VF2. Red indicates principal factor1 and blue indicates principal factor2. VF, varifactor; PF, principal factor; WT, water temperature; DO, dissolved oxygen; BOD, biochemical oxygen demand; COD, chemical oxygen demand; TOC, total organic carbon; TSS, total suspended solids; EC, electrical conductivity; $\mathrm{TN}$, total nitrogen; $\mathrm{NH}_{3}-\mathrm{N}$, ammonia-nitrogen; $\mathrm{NO}_{3}-\mathrm{N}$, nitrate-nitrogen; $\mathrm{PO}_{4}-\mathrm{P}$, phosphate-phosphorus; TP, total phosphorus; Chl-a, chlorophyll-a; FC, fecal coliform 

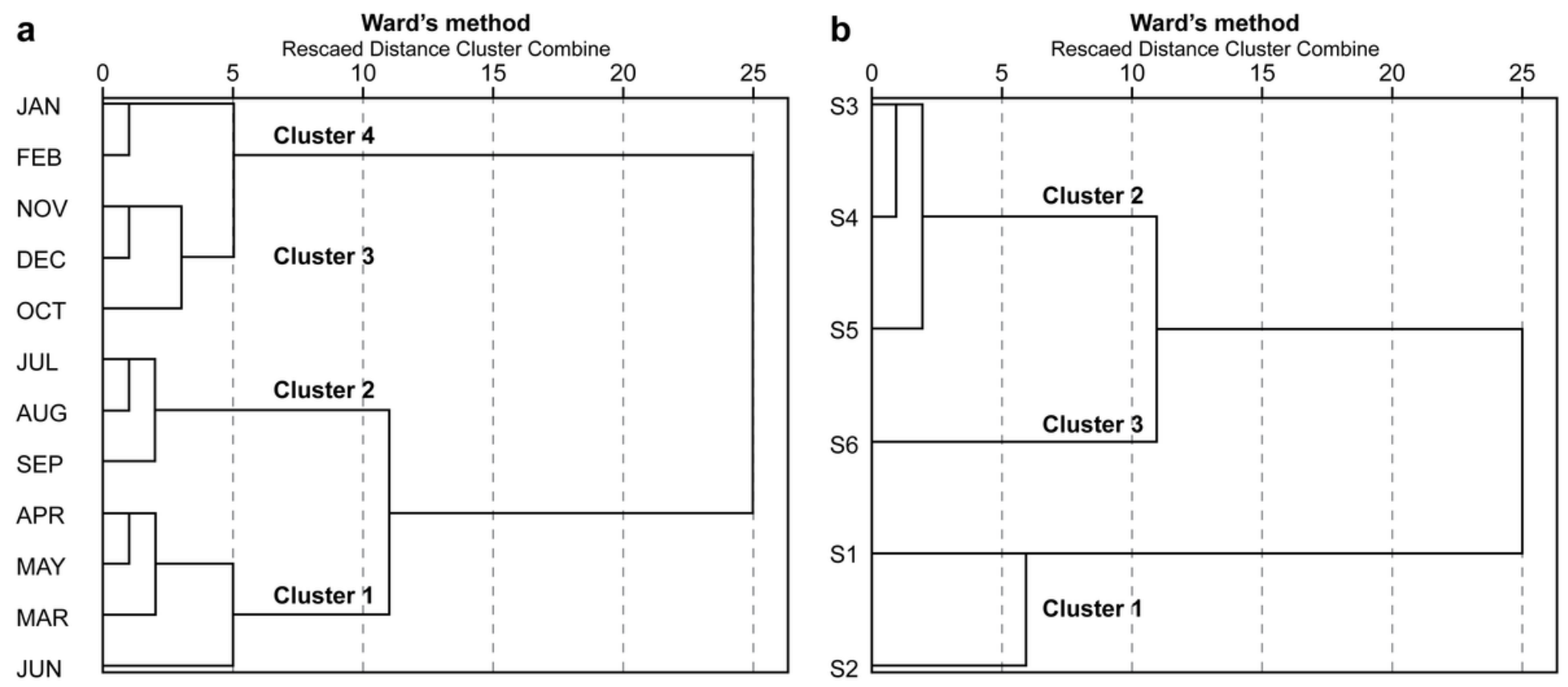

Figure 3

Dendrograms that show seasonal and spatial clusters. a: seasonal cluster analysis; b: spatial cluster analysis

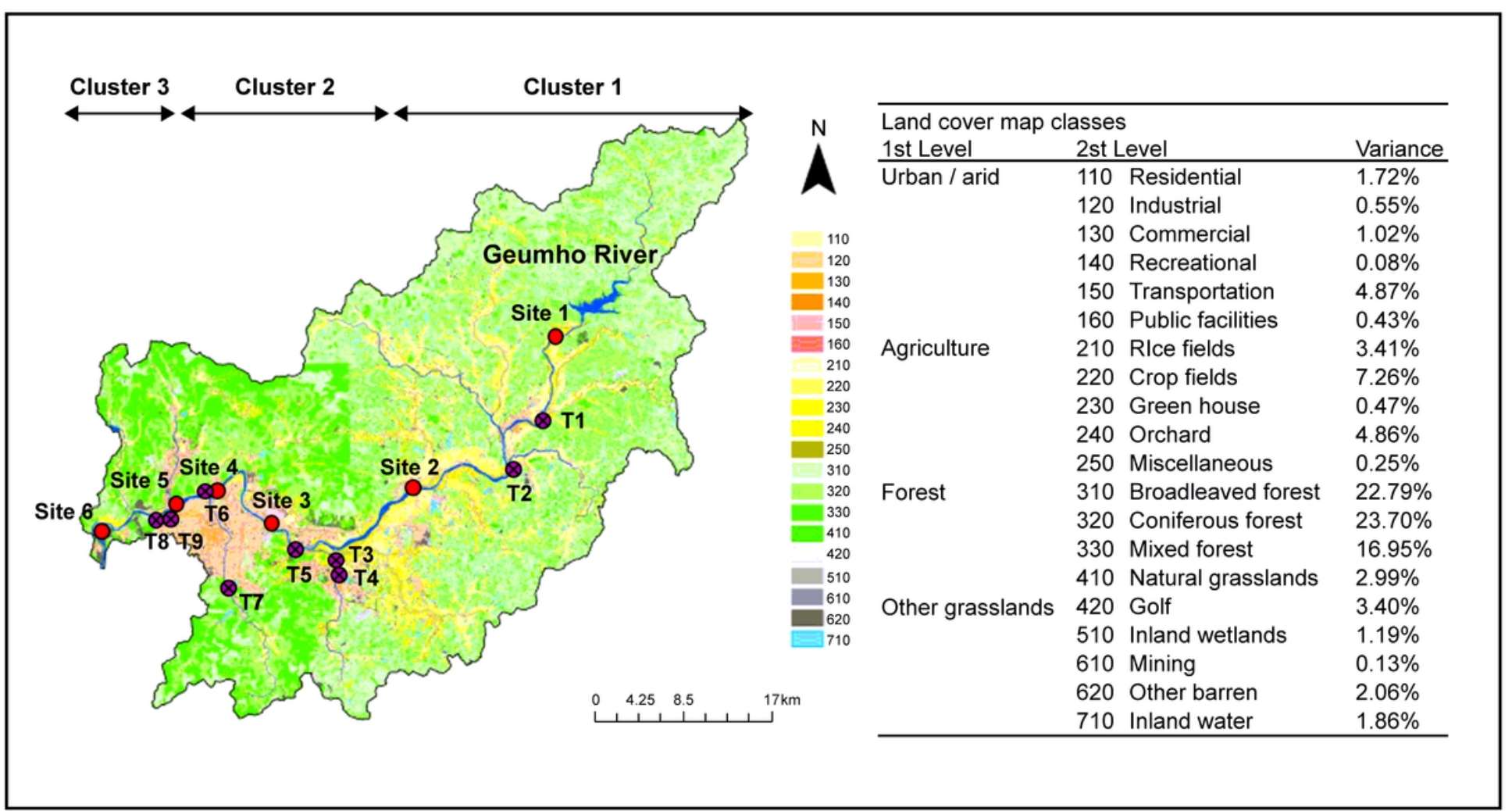

\section{Figure 4}

Land cover map of the target watershed drawn using Arc-GIS. Land cover codes 110 to 160 are urban (orange series), 210 to 250 are agriculture (yellow series), 310 to 330 are forest (green series), etc. Red point, monitoring sites (S1 to S6); purple point, sewage and wastewater treatment facilities (T1 to T9) 
a
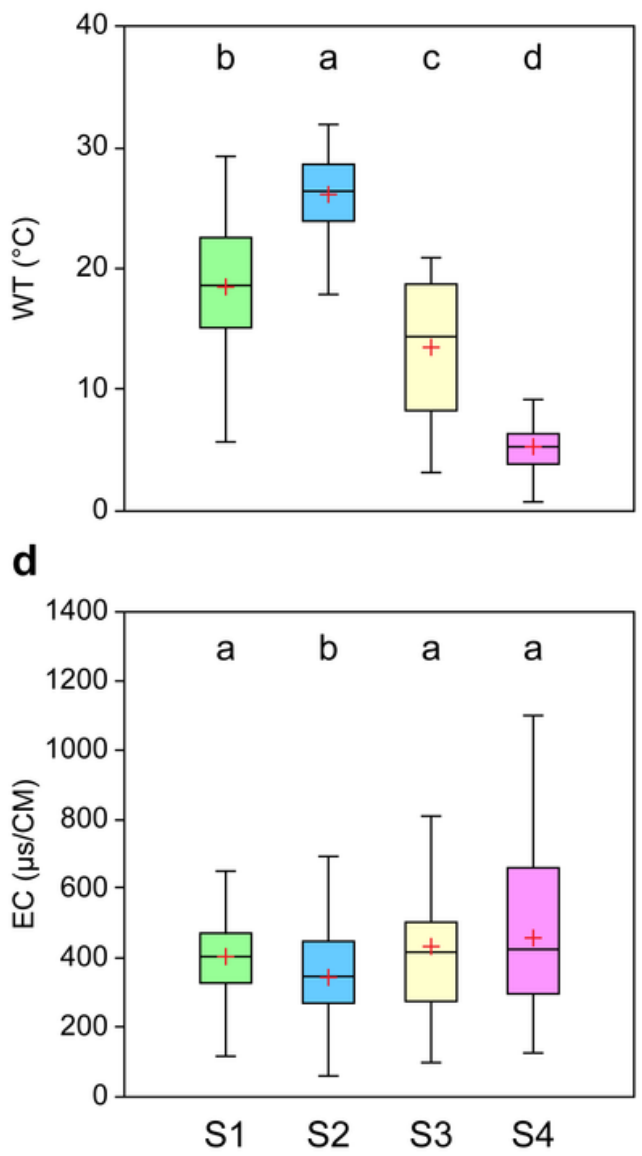

b

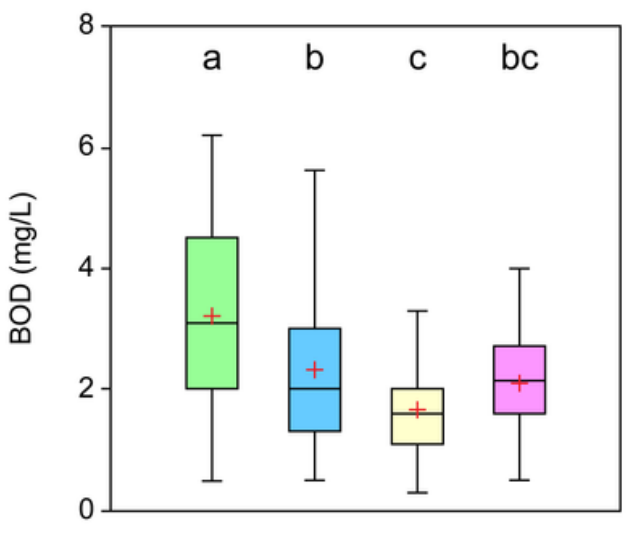

e

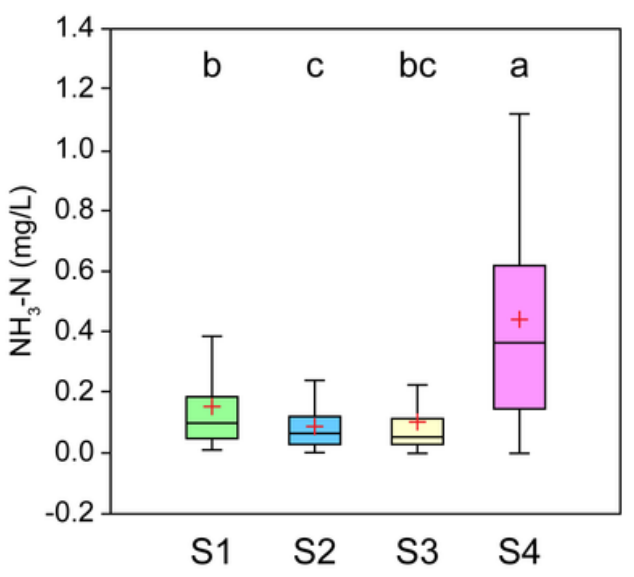

C
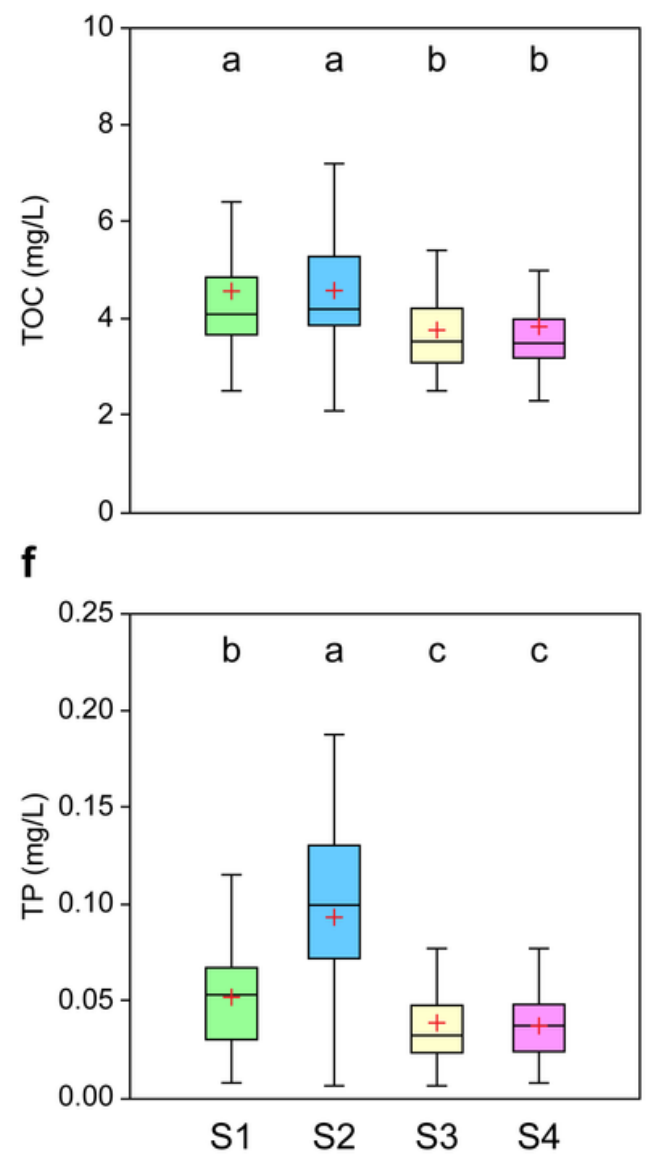

Figure 5

Box plots of the temporal stepwise mode discriminant function. The middle line of each box represents the median value, the lower line represents the first quartile (25\%), the upper line represents the third quartile (75\%), the lower bar represents the minimum (median-1.5 $\times$ interquartile range; IQR), and the upper bar represents the maximum (median $+1.5 \times \mathrm{IQR}$ ); the red cross mark indicates the average value. IQR is the third quartile minus the first quartile, and the letters above the box plot represent the results of the Scheffe Test $(p<0.05)$. a: water temperature; b: biochemical oxygen demand; c: total organic carbon; d: electrical conductivity; e: ammonianitrogen; $f$ : total phosphorus.

S1, spring; S2, summer; S3, autumn; S4, winter 
a

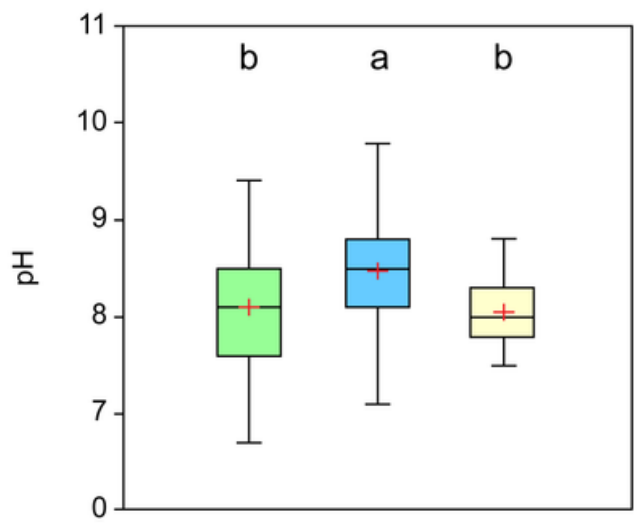

d

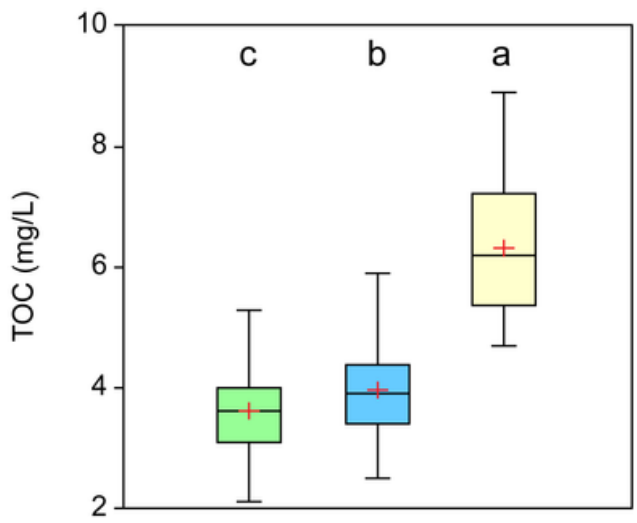

g

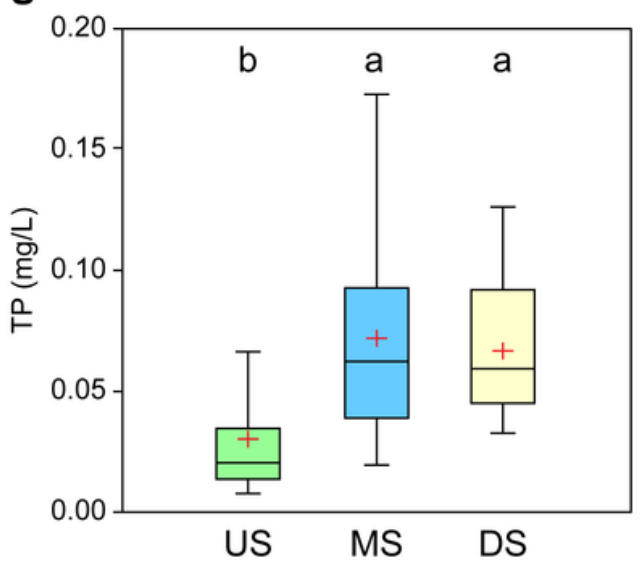

b

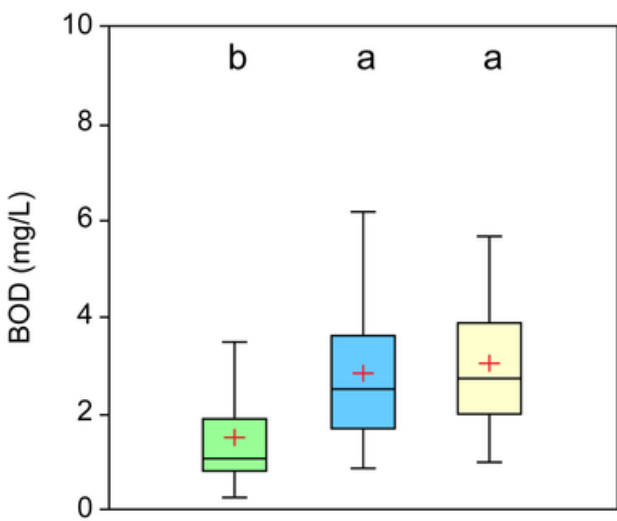

e

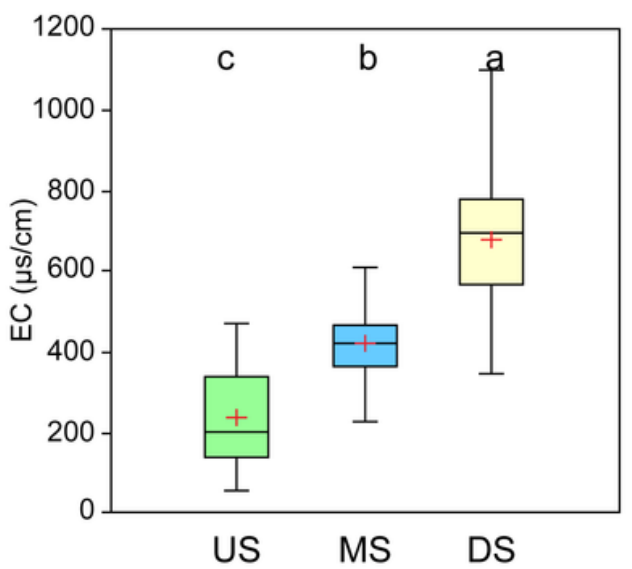

C

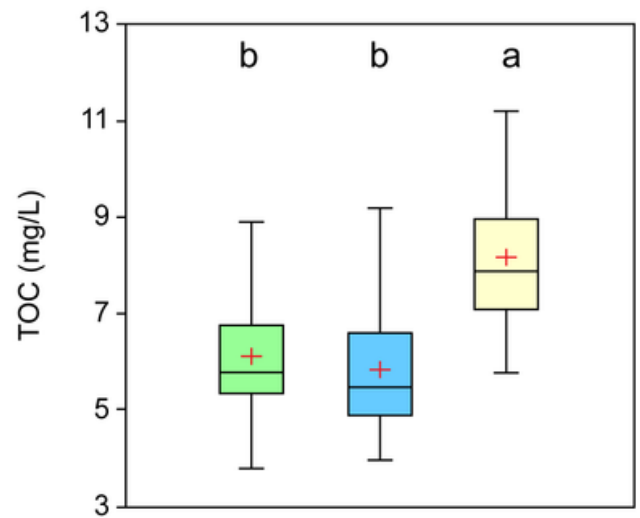

f

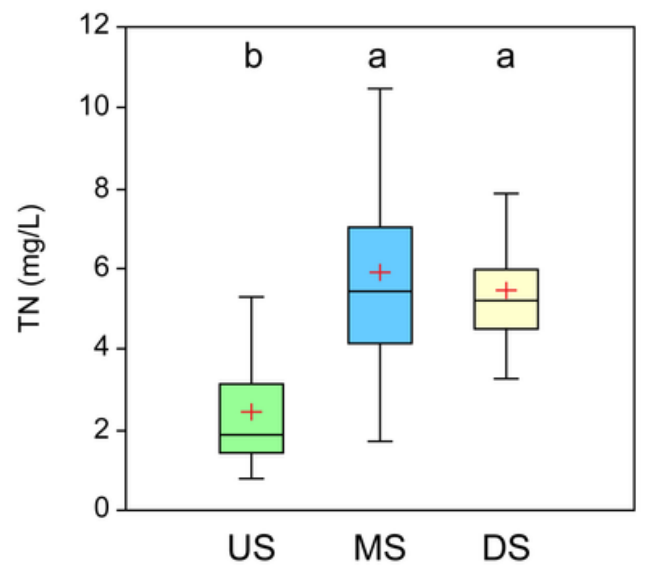

\section{Figure 6}

Box plots of the spatial stepwise mode discriminant function. The middle line of each box represents the median value, the lower line represents the first quartile (25\%), the upper line represents the third quartile (75\%), the lower bar represents the minimum (median-1.5 $\times$ interquartile range; IQR), and the upper bar represents the maximum (median + $1.5 \times \mathrm{IQR}$ ); the red cross mark indicates the average value. IQR is the third quartile minus the first quartile, and the letters above the box plot represent the results of the Scheffe Test $(p<0.05)$. $a$ : $p H ; b$ : biochemical oxygen demand; c: chemical oxygen demand; d: total organic carbon; e: electrical conductivity; f: total nitrogen; g: total phosphorus. US, upstream; MS, middle stream; DS, downstream 
a

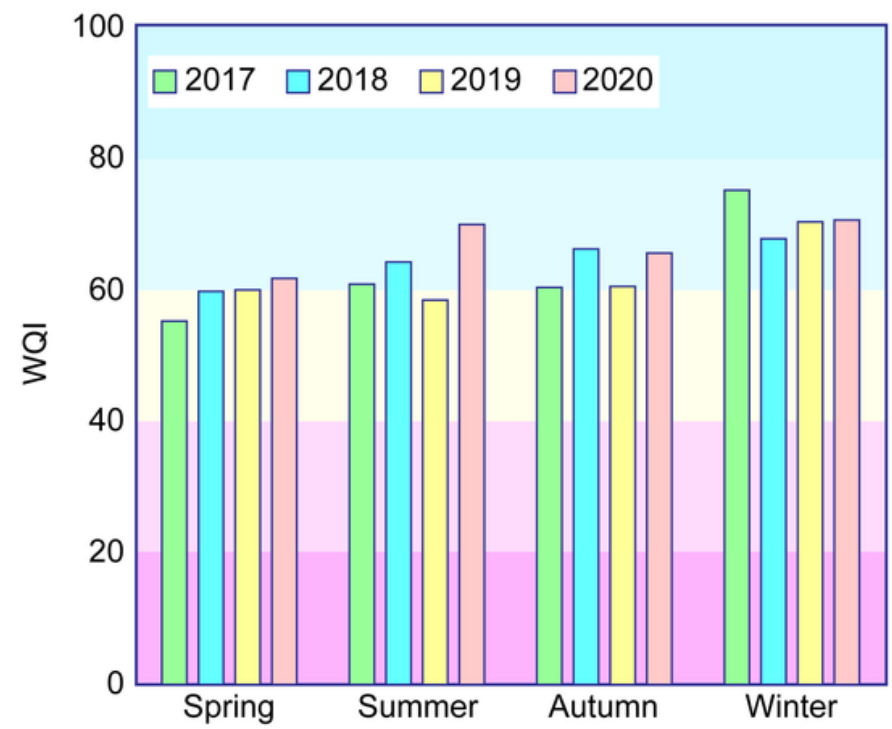

b

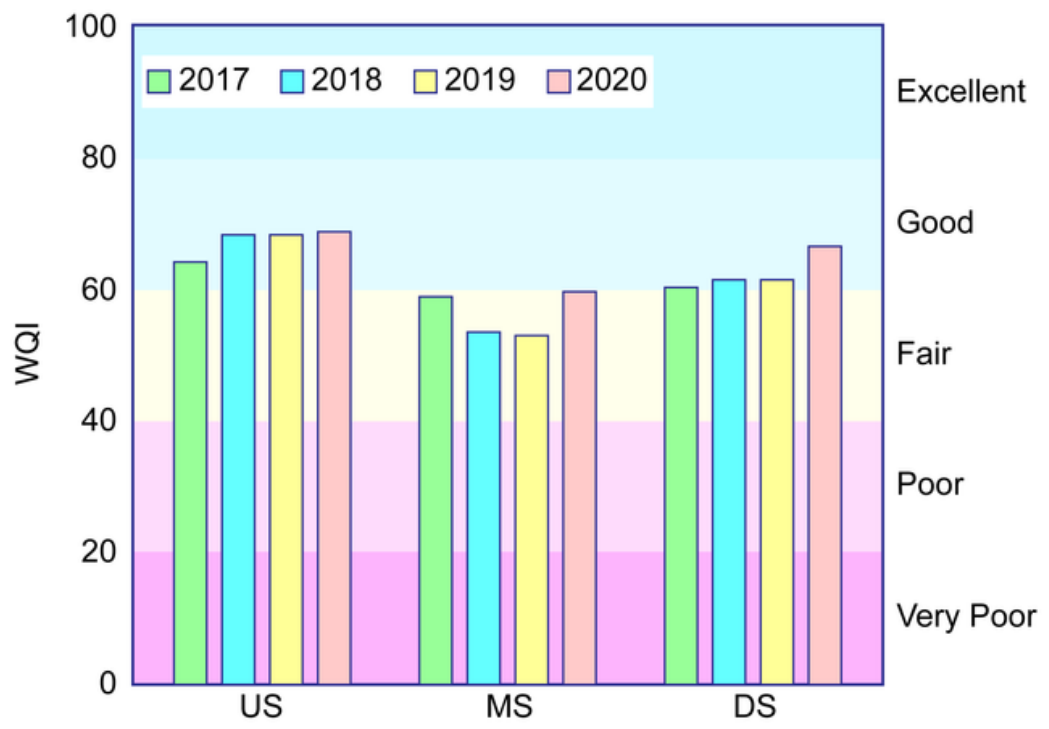

Figure 7

Seasonal and spatial water quality index (WQI) scores. Four bar graphs in each seasonal or spatial group show WQI scores from 2017 to 2020 from the left to right. The letters on the right represent the water quality grades of the WQI. Excellent, Suitable for hydrophilic activities with clean water; Good, Suitable for hydrophilic activities with good water; Fair, sometimes pollutants may be introduced and affect hydrophilic activity; Poor, Attention of hydrophilic activities due to frequent inflow of pollutants; Very poor, Inadequate for hydrophilic activities with high water pollution level. WQI, water quality index; a, seasonal WQI; b, spatial WQI 